\title{
DOSES E FONTES DE NITROGÊNIO EM FERTIRRIGAÇÃO NO CULTIVO DO MARACUJÁ-AMARELO ${ }^{1}$
}

\author{
ANA LÚCIA BORGES², RANULFO CORRÊA CALDAS², ADELISE DE ALMEIDA LIMA²
}

\begin{abstract}
RESUMO - Vários fatores influenciam na produtividade do maracujazeiro, dentre os quais o clima, o solo e as práticas de adubação e de irrigação. A nutrição mineral é essencial para elevar a produtividade e melhorar a qualidade dos frutos, e o nitrogênio é o nutriente mais absorvido pelo maracujazeiro. O trabalho objetivou avaliar doses e fontes de nitrogênio, aplicadas em fertirrigação, em 17 meses de produção do maracujáamarelo (Passiflora edulis Sims f. flavicarpa Deg.), na produção e qualidade dos frutos, em Latossolo Amarelo de Tabuleiro Costeiro do Estado da Bahia. Estudaram-se, em blocos casualizados com parcelas subdivididas, duas fontes de $\mathrm{N}$ (uréia e nitrato de cálcio), nas parcelas, e cinco doses de $\mathrm{N}\left(0 ; 100 ; 200 ; 400\right.$ e $\left.800 \mathrm{~kg} \mathrm{ha}^{-1}\right)$, nas subparcelas, com três repetições. O maracujá-amarelo foi plantado no espaçamento de 3,00 x 1,25 $\mathrm{m}$, contendo a subparcela oito plantas úteis, com bordadura simples, e avaliado no período de janeiro de 2000 a janeiro de 2002 . Os resultados mostraram que a produtividade máxima de frutos, $34,3 \mathrm{tha}^{-1}$, foi obtida com aplicação de $457 \mathrm{~kg}$ de $\mathrm{N}_{\text {ha }}{ }^{-1}$, na forma de uréia. Contudo, a adubação nitrogenada e as fontes utilizadas não influenciaram nas características do fruto e na qualidade do suco.
\end{abstract}

Termos de indexação: Passiflora edulis Sims f. flavicarpa Deg., Latossolo Amarelo coeso, Tabuleiro Costeiro, uréia, nitrato de cálcio.

\section{SOURCES AND DOSES OF NITROGEN IN FERTIRRIGATION OF YELLOW PASSION-FRUIT CULTIVATION}

ABSTRACT - Passion fruit yield is influenced by several production factors, among them the climate, the soil and the manuring and irrigation practices. Nitrogen $(\mathrm{N})$ is the most absorbed nutrient by the passion-fruit plant and has structural functions in the plant, and it can be supplied by nitric, ammoniacal and starchy sources. The experiment objective was to evaluate nitrogen sources and doses applied in fertirrigation of passion-fruit (Passiflora edulis Sims f. flavicarpa Deg.) production and fruit quality in 17 months of production in a Coastal Tableland Yellow Latosol in Bahia State, Brazil. It was studied, in randomized blocks with split-plots, two sources of N (urea and calcium nitrate), on the plots, and five $\mathrm{N}$ doses $\left(0,100,200,400\right.$ and $\left.800 \mathrm{~kg} \mathrm{ha}^{-1}\right)$, on the split-plots with three replicas. The yellow passion-fruit was planted in a spacing of $3.00 \mathrm{x}$ $1.25 \mathrm{~m}$, in a total area of $1,237.50 \mathrm{~m}^{2}$, and evaluated from january 2000 to january 2002 . The results showed maximum yield of 34 ton ha-1 applying $457 \mathrm{~kg}$ of $\mathrm{N} \mathrm{ha}^{-1}$, in urea form. Nitrogen fertilizer and sources did not interfer in the fruit characteristics and juice quality.

Index terms: Passiflora edulis Sims f. flavicarpa Deg., Yellow Latosol, Coastal Tableland, urea, calcium nitrate.

\section{INTRODUÇÃO}

A produtividade do maracujazeiro é influenciada por vários fatores, dentre os quais o clima, o solo e as práticas culturais, incluindo adubação e irrigação. A nutrição mineral é essencial para elevar a produtividade e melhorar a qualidade dos frutos. Os nutrientes fornecidos por meio da adubação química devem ser aplicados em níveis compatíveis com as exigências da planta e com a forma de adubação utilizada. A aplicação via água de irrigação, fertirrigação, é hoje de comprovada eficácia, principalmente quando se utilizam fertilizantes com elevado grau de solubilidade, pois alia os dois componentes, água e nutrientes. Nos processos de absorção por fluxo de massa e difusão, a água é de fundamental importância na translocação dos nutrientes; e 99\% da absorção de nitrogênio ocorre por fluxo de massa (Malavolta et al., 1989).

O nitrogênio é o nutriente mais absorvido pelo maracujazeiro, na quantidade de $205 \mathrm{~kg} \mathrm{ha}{ }^{-1}$, aos 370 dias de idade, com 1.500 plantas ha ${ }^{-1}$ (Haag et al., 1973). Tem função estrutural na planta e faz parte de moléculas de aminoácidos e proteínas, além de ser constituinte de bases nitrogenadas e ácidos nucléicos. Esse nutriente atua em processos como absorção iônica, fotossíntese, respiração, multiplicação e diferenciação celular (Malavolta et al., 1989), é fundamental no crescimento, na formação vegetativa da planta e na produção (Kliemann et al., 1986; Baumgartner, 1987), estimula o desenvolvimento de gemas floríferas e frutíferas e aumenta o teor de proteínas (Malavolta et al., 1989).

Maior produtividade e quantidade de sólidos solúveis totais, bem como menor acidez do suco foram obtidas para o maracujazeiro

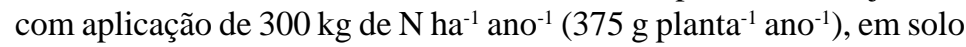
de tabuleiro do Estado da Bahia (Borges et al., 1998). No Estado do Rio de Janeiro, a produtividade máxima $\left(41,3 \mathrm{tha}^{-1}\right)$ foi obtida com a

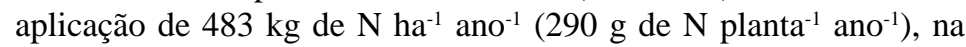
forma de uréia (Carvalho et al., 2000), no período de 18 meses. Esses autores verificaram também que a adubação nitrogenada não influenciou nas características qualitativas dos frutos, com médias de rendimento em suco de $35,6 \%$, e diâmetro e comprimento do fruto, respectivamente, de 69,5 $\mathrm{mm}$ e 73,7 $\mathrm{mm}$. Dutra et al. (2003) estudaram a adubação nitrogenada, na forma de uréia, nas doses de 50 a $450 \mathrm{~g}$ planta $^{-1}$ ano $^{-1}$, nos sistemas fertirrigado (semanal) e manual (mensal), na qualidade dos frutos de maracujá-amarelo e constataram maiores peso médio do fruto $(231 \mathrm{~g})$, diâmetro $(84,7 \mathrm{~mm})$, acidez titulável $(4,21)$, sólidos solúveis totais $(12,3)$ e $\mathrm{pH}(2,83)$, quando o nitrogênio foi aplicado via água de irrigação.

O nitrogênio apresenta alta mobilidade no solo e livre movimentação com a água de irrigação, principalmente na forma de nitrato $\left(\mathrm{NO}_{3}^{-}\right)$, pois não é retido pela argila (Tisdale \& Nelson, 1991). Os fertilizantes nitrogenados sólidos são apresentados em quatro formas: amoniacal, nítrica, nítrico-amoniacal e amídica, sendo solúveis em água e adequados para fertirrigação, inclusive por gotejamento. De modo geral, as fontes nitrogenadas têm apresentado comportamento similar, podendo diferir em razão da presença de outro nutriente na mesma ou pelo efeito que exercem sobre o $\mathrm{pH}$ do solo, acidificante, como no caso do sulfato de amônio e uréia (Coelho, 1994). A escolha da fonte do fertilizante deve basear-se em vários fatores, incluindo disponibilidade do produto no mercado, preço, época, modo de aplicação e sistemas de manejo, dentre outros (Borges $\&$ Cardoso, 2003). A uréia é o fertilizante nitrogenado mais utilizado, devido ao menor preço por unidade de nutriente. Apresenta $450 \mathrm{~g}$ de $\mathrm{N} \mathrm{kg}^{-1}$, solubilidade de $1.000 \mathrm{~g} \mathrm{~L}^{-1}$, índice salino por unidade de nutriente de 1,70 (índice relativo comparado com o fertilizante nitrato de sódio, $\mathrm{NaNO}_{3}$ ) e índice de acidez de $71 \%$, ou seja, são necessários $71 \mathrm{~kg}$ de $\mathrm{CaCO}_{3}$ para neutralizar $100 \mathrm{~kg}$ de uréia (Borges \& Silva, 2002). O uso de um fertilizante não-ácido, como o nitrato de cálcio $\left(155 \mathrm{~g} \mathrm{de} \mathrm{N} \mathrm{kg}^{-}\right.$ ${ }^{1}$ e $190 \mathrm{~g} \mathrm{de} \mathrm{Ca} \mathrm{kg}^{-1}$ ), que contém também cálcio, o terceiro nutriente mais absorvido pelo maracujazeiro $\left(152 \mathrm{~kg} \mathrm{ha}^{-1}\right)$, de alta solubilidade (1.200 $\left.\mathrm{g} \mathrm{L}^{-1}\right)$, pode ser uma alternativa, apesar de o índice salino por

\footnotetext{
${ }^{1}$ (Trabalho 020-2005). Recebido: 24-01-2005. Aceito para publicação: 10-05-2006.

${ }^{2}$ Eng (a). Agr (a)., Pesquisador (a) da Embrapa Mandioca e Fruticultura Tropical. Caixa Postal 007, CEP 44380-000 Cruz das Almas-BA. E-mails: analucia@cnpmf.embrapa.br; rcaldas@cnpmf.embrapa.br; adelise@cnpmf.embrapa.br.
} 
unidade de nutriente ser de 4,07.

O trabalho objetivou avaliar doses e fontes de nitrogênio em fertirrigação, na produção e qualidade dos frutos do maracujá-amarelo (Passiflora edulis Sims f. flavicarpa Deg), em Latossolo Amarelo de Tabuleiro Costeiro do Estado da Bahia.

\section{MATERIAL E MÉTODOS}

O experimento foi instalado em janeiro de 2000, na área experimental da Embrapa Mandioca e Fruticultura Tropical, no Município de Cruz das Almas, Região do Recôncavo Baiano, a 1240'19" de latitude sul, 3906'22" de longitude oeste Gr e altitude de $220 \mathrm{~m}$. O solo é um Latossolo Amarelo álico coeso franco-argiloarenoso (609 g de areia kg-1, $114 \mathrm{~g}_{\text {de silte } \mathrm{kg}^{-1} \mathrm{e} 277 \mathrm{~g} \text { de argila kg}}{ }^{-1}$ ), com as seguintes propriedades químicas, na camada de $0-20 \mathrm{~cm}$ de profundidade: $\mathrm{pH}$ em água=5,6; $\mathrm{P}$ (Mehlich 1) $=4,0 \mathrm{mg} \mathrm{dm}^{-3} ; \mathrm{K}=164 \mathrm{mg} \mathrm{dm}^{-3} ; \mathrm{Ca}=2,2 \mathrm{cmol}_{\mathrm{c}} \mathrm{dm}^{-}$ 3; $\mathrm{Mg}=1,5 \mathrm{cmol}_{\mathrm{c}} \mathrm{dm}^{-3} ; \mathrm{CTC}=7,2 \mathrm{cmol}_{\mathrm{c}} \mathrm{dm}^{-3} ; \mathrm{V}=59 \%$ e matéria orgânica $=18,8 \mathrm{~g} \mathrm{~kg}^{-1}$, segundo metodologia proposta pela Embrapa (1997). O clima da região é subúmido, com temperatura média anual de $24^{\circ} \mathrm{C}$, umidade relativa do ar média anual de $80 \%$ (Souza \& Souza, 2001). A precipitação no período de janeiro/2000 a janeiro/2002 foi de $2.866,4$ $\mathrm{mm}$, variando de $8,9 \mathrm{~mm}$ em novembro de 2001 a $240,9 \mathrm{~mm}$ em janeiro de 2002, com maior concentração de chuva nos meses de maio a agosto.

$\mathrm{O}$ delineamento experimental utilizado foi em blocos casualizados, com parcelas subdivididas, colocando-se nas parcelas as fontes de $\mathrm{N}$ (uréia $-450 \mathrm{~g}_{\text {de }} \mathrm{N} \mathrm{kg}^{-1}$ e nitrato de cálcio - $155 \mathrm{~g}$ de N

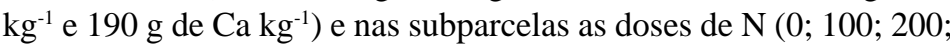
400 e $800 \mathrm{~kg} \mathrm{ha}^{-1}$ ), com três repetições. O maracujá-amarelo (Passiflora edulis Sims f. flavicarpa Deg.) foi plantado no espaçamento de 3,00 x $1,25 \mathrm{~m}$ (2.666 plantas ha $\left.{ }^{-1}\right)$, contendo a subparcela útil oito plantas em uma única linha, com bordadura simples por se tratar de irrigação localizada. A calagem foi aplicada em toda a área, na quantidade de 2,6 t de calcário dolomítico ha-1 ${ }^{-1}$, visando a elevar a saturação por bases para $80 \%$ e incorporado com grade a uma profundidade de $20 \mathrm{~cm}$. Na cova de plantio, foram aplicados 15 litros de esterco de curral

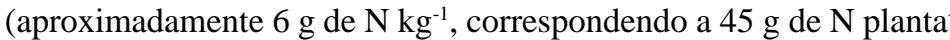
${ }^{1}$ ), $40 \mathrm{~kg}$ de $\mathrm{P}_{2} \mathrm{O}_{5}$ ha $^{-1}$ (superfosfato simples) e $50 \mathrm{~g}$ de FTE BR12 (2,17\% de B; $0,80 \%$ de $\mathrm{Cu} ; 3,85 \%$ de Fe; 3,48\% de $\mathrm{Mn} ; 0,13 \%$ de $\mathrm{Mo}$ e $9,24 \%$ de $\mathrm{Zn}$ ). O fósforo foi aplicado em cobertura, no primeiro ano, na dose de $160 \mathrm{~kg}$ de $\mathrm{P}_{2} \mathrm{O}_{5}$ ha ${ }^{-1}$, na forma de superfosfato simples, manualmente, não sendo necessária a aplicação de potássio, em razão do teor no solo acima de $120 \mathrm{mg} \mathrm{dm}^{-3}$ (Borges, 1999). No segundo ano, foram aplicados $50 \mathrm{~g}$ de FTE BR12 (única aplicação), $80 \mathrm{~kg}$ de $\mathrm{P}_{2} \mathrm{O}_{5}$ ha ${ }^{1}$ (única aplicação na floração) e $400 \mathrm{~kg} \mathrm{de} \mathrm{K}_{2} \mathrm{O} \mathrm{ha}^{-1}$ ano $^{-1}$ (Borges, 1999), este aplicado na forma de cloreto de potássio via água. A fertirrigação com nitrogênio e potássio foi feita por gotejamento a cada sete dias, iniciando-se um mês após o plantio, em parcelas iguais. Foram colocados dois gotejadores autolimpantes e autocompensantes, com vazão de $3,75 \mathrm{~L} \mathrm{~h}^{-1}$ por planta em linha contínua distante $60 \mathrm{~cm}$ entre eles e a $30 \mathrm{~cm}$ do caule das plantas. Na bordadura, as plantas foram adubadas com $200 \mathrm{~kg} \mathrm{de} \mathrm{N} \mathrm{ha}^{-1} \mathrm{ano}^{-1} \mathrm{e} 400 \mathrm{~kg}$ de $\mathrm{K}_{2} \mathrm{O}$ $\mathrm{ha}^{-1}$, este apenas no segundo ano, manualmente, na forma sólida.

A polinização foi natural no primeiro ano e manual a partir do $12^{\circ}$ mês. Foi realizado o controle de pragas e doenças quando necessário e alternaram-se capinas manuais e herbicidas.

As colheitas foram realizadas três vezes por semana, no período de setembro de 2000 a janeiro de 2002, colhendo-se os frutos caídos no chão para contagem, pesagem, classificação e medição do comprimento e diâmetro equatorial com o auxílio de um paquímetro.

Foram avaliados dados de 17 meses de produção (número de frutos totais, para indústria e para consumo in natura, peso médio, comprimento e diâmetro equatorial do fruto) e qualidade do suco (rendimento, $\mathrm{pH}$, sólidos solúveis totais - SST, acidez - AC e relação SST/AC). Além disso, foi avaliada a sanidade dos frutos quanto à presença de doenças (antracnose e verrugose), em relação à fonte nitrogenada.

Para avaliação das características físico-químicas do fruto (sólidos solúveis totais - SST, acidez titulável - AT, relação SST/AT e rendimento em suco), foram utilizados dez frutos por tratamento, com duas avaliações ao ano. O suco foi obtido batendo-se a polpa no liquidificador, sem danificar as sementes, passando em seguida por peneira de malha fina e medindo-se o seu volume em uma proveta. Para a determinação do teor de SST no suco, utilizou-se um refratômetro de laboratório ABBE MARK II digital. A acidez titulável foi determinada em amostras de $10 \mathrm{~mL}$ de suco, titulando com solução de $\mathrm{NaOH} 0,1 \mathrm{~N}$, usando-se a fenolftaleína $\left(30 \mathrm{~g} \mathrm{~L}^{-1}\right)$ como indicador.

As variáveis respostas foram avaliadas estatisticamente pelos procedimentos da análise de variância (Teste F) e estimados modelos lineares para as duas fontes de nitrogênio, uréia e nitrato de cálcio, usando o programa SAS (2005).

\section{RESULTADOS E DISCUSSÃO}

Os dados de 17 meses de produção analisados segundo o delineamento experimental proposto mostraram que não houve diferença significativa (Teste $\mathrm{F}>5 \%$ ) para as variáveis avaliadas, tanto para fonte quanto para doses de nitrogênio (Tabela 1). Possivelmente, a aplicação de aproximadamente $45 \mathrm{~g}$ de N por planta

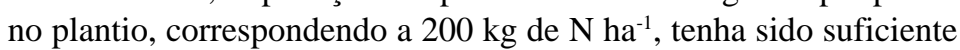
para suprir as necessidades das plantas. No entanto, deve-se lembrar que o nitrogênio tem importância fundamental na planta (Kliemann et al., 1986; Baumgartner, 1987; Malavolta et al., 1989).

TABELA 1 - Médias das variáveis de produção do maracujá-amarelo avaliadas em 17 meses, em função de fontes e doses de nitrogênio. Cruz das Almas-BA, janeiro/2000-janeiro/2002.

\begin{tabular}{|c|c|c|c|c|c|c|c|}
\hline Fontes de N & NFT $^{1}$ & NFN & NFI & $\begin{array}{c}\text { PMF } \\
\text { (g) }\end{array}$ & $\begin{array}{l}\mathrm{COF} \\
(\mathrm{cm})\end{array}$ & $\begin{array}{l}\text { DIF } \\
\text { (cm) }\end{array}$ & $\begin{array}{l}\text { PRD } \\
\text { (t/ha) }\end{array}$ \\
\hline Uréia & 235.664 & 72.333 & 163.331 & 137,8 & 7,87 & 6,94 & 32,3 \\
\hline Nitrato de cálcio & 248.331 & 75.333 & 172.998 & 139,7 & 7,84 & 7,02 & 34,6 \\
\hline Teste F & ns & ns & ns & ns & ns & ns & ns \\
\hline \multicolumn{8}{|c|}{ Doses de N $\left(\mathrm{kg} \mathrm{ha}^{-1} \mathrm{ano}^{-1}\right)$} \\
\hline 0 & 238.331 & 70.666 & 167.665 & 138,3 & 7,90 & 6,98 & 32,7 \\
\hline 100 & 255.997 & 79.999 & 175.998 & 138,9 & 7,85 & 6,96 & 35,6 \\
\hline 200 & 228.664 & 70.333 & 158.331 & 138,2 & 7,80 & 6,98 & 31,5 \\
\hline 400 & 245.998 & 76.659 & 169.339 & 137,9 & 7,75 & 6,97 & 33,7 \\
\hline 800 & 240.664 & 70.999 & 169.665 & 140,4 & 7,97 & 7,00 & 33,7 \\
\hline Teste F & ns & ns & ns & ns & ns & ns & ns \\
\hline$\overline{C V(\%)}$ & 18,6 & 11,7 & 23,8 & 5,8 & 2,5 & 2,4 & 18,8 \\
\hline Média geral & 241.998 & 73.666 & 168.332 & 138,7 & 7,85 & 6,98 & 33,5 \\
\hline
\end{tabular}

${ }^{1} \mathrm{NFT}=$ número de frutos totais/ha; NFN=número de frutos para consumo in natura/ha; NFI=número de frutos destinados à indústria/ha; PMF=peso médio do fruto; $\mathrm{COF}=$ comprimento médio do fruto; $\mathrm{DIF}=$ diâmetro médio do fruto; $\mathrm{PRD}=$ produtividade. 
Apesar de não haver diferença estatística, o número total, peso médio e diâmetro médio do fruto foram, respectivamente, $5,4 \%$; $1,4 \%$ e $1,2 \%$ maiores com a fonte nitrato de cálcio. Já o comprimento médio do fruto foi $0,03 \mathrm{~cm}$ maior nos tratamentos adubados com uréia. Carvalho et al. (2000) também não constataram efeito da adubação nitrogenada nas características do fruto, obtendo comprimento e diâmetro menores nos frutos, comparados com os obtidos nesse trabalho.

Para produtividade, foi feito o desdobramento, analisandose o comportamento das doses dentro de cada fonte de nitrogênio. No modelo estimado para a fonte uréia, obteve-se a dose de $457 \mathrm{~kg}$ de $\mathrm{N} \mathrm{a}^{-1}$ para a produtividade máxima de $34,3 \mathrm{t} \mathrm{ha}^{-1}$ (Figura 1). Carvalho et al. (2000) obtiveram, também com o uso da uréia, produtividade de 41,3 t ha ${ }^{-1}$, com a aplicação de $483 \mathrm{~kg}$ de $\mathrm{N} \mathrm{ha}^{-1}$, em 18 meses de produção, porém em um solo tipo Podzólico (Alissolo). Comportamento inverso foi verificado para o modelo estimado para a fonte nitrato de cálcio que apresentou produtividade mínima de 32,8 t ha $^{-1}$ para a dose de $228 \mathrm{~kg}$ de N ha-1 (Figura 1 ).

O decréscimo da produtividade com a aplicação de doses mais elevadas de nitrogênio é possivelmente atribuído à função do $\mathrm{N}$ no crescimento vegetativo, resultando em alta produção de folhas e diminuição do número de flores.

Quanto à qualidade do suco, não houve diferença estatística entre fontes de nitrogênio, apesar de o nitrato de cálcio ter proporcionado rendimento em suco, teores de sólidos solúveis totais (SST) e acidez titulável, respectivamente, $0,7 \%, 1,4 \%$ e $4,4 \%$ maiores. Também não houve diferença estatística entre doses de nitrogênio (Tabela 2). Acredita-se que tanto a aplicação do esterco de curral no plantio, quanto a matéria orgânica do solo tenham contribuído para a não-resposta do maracujazeiro ao $\mathrm{N}$.

A média geral de rendimento em suco foi de $29,8 \%$, o pH de 3,08 , o teor de sólidos solúveis totais (SST) de 14,2, a acidez (AC) de 4,6 g/100 g e a relação SST/AC de 3,1 (Tabela 2). Segundo Tocchini et al. (1995), a composição média do suco de maracujá-amarelo apresentou valores de 15,0\% de SST, 4,0 g/100 g de acidez e pH de 3,0; os resultados obtidos neste trabalho estão próximos aos citados por

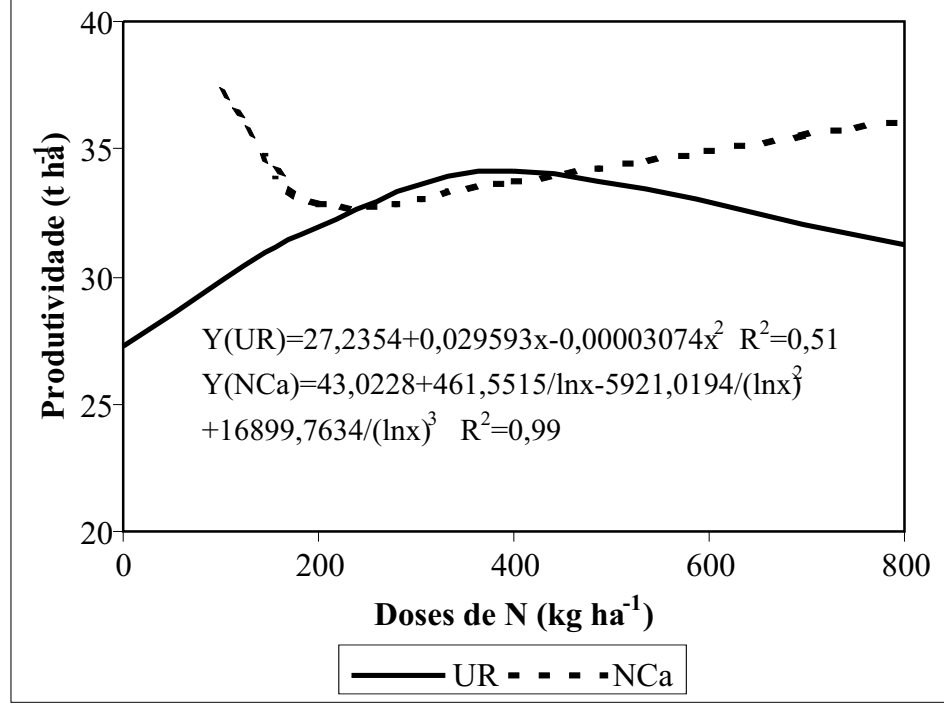

FIGURA 1 - Equações estimadas para a produtividade do maracujáamarelo, em 17 meses, em função das doses de $\mathrm{N}$ dentro de cada fonte (uréia - UR - e nitrato de cálcio - NCa) em fertirrigação. Cruz das Almas-BA, janeiro/2000-janeiro/ 2002.

esse autor. Carvalho et al. (2000) também não verificaram efeito da adubação nitrogenada na qualidade do suco, tanto no rendimento quanto na quantidade de SST e $\mathrm{pH}$, porém obtiveram maior valor no rendimento em suco $(35,6 \%)$, menor quantidade de SST e $\mathrm{pH}$ mais baixo. Dutra et al. (2003) também observaram valores inferiores para acidez, SST e pH do suco.

Quanto à incidência de doenças nos frutos, a verrugose foi a mais encontrada (Tabela 3), pois a alta umidade relativa do ar da região (Souza \& Souza, 2001) e as chuvas distribuídas com maior intensidade nos meses de maio a agosto favoreceram o aparecimento das doenças nos frutos, apesar de se ter utilizado o controle químico, quando necessário. A presença de verrugose nos frutos desvaloriza o produto, principalmente na sua comercialização in natura.

TABELA 2 - Médias das variáveis para qualidade do suco de maracujá-amarelo, em 17 meses de produção, em função de fontes e doses de nitrogênio. Cruz das Almas-BA, janeiro/2000-janeiro/2002.

\begin{tabular}{|c|c|c|c|c|c|}
\hline Fontes de N & $\begin{array}{c}\text { Rend. }^{\top} \\
(\%)\end{array}$ & pH & $\begin{array}{l}\text { SST } \\
(\%)\end{array}$ & $\begin{array}{c}\mathrm{AC} \\
\left(\mathrm{g} 100 \mathrm{~g}^{-1}\right)\end{array}$ & SST/AC \\
\hline Uréia & 29,8 & 3,08 & 14,1 & 4,5 & 3,1 \\
\hline Nitrato de cálcio & 30,0 & 3,07 & 14,3 & 4,7 & 3,1 \\
\hline Teste F & Ns & ns & ns & ns & ns \\
\hline \multicolumn{6}{|c|}{ Doses de N (kg ha ${ }^{-1}$ ano $\left.^{-1}\right)$} \\
\hline$\overline{0}$ & 30,0 & 3,15 & 14,1 & 4,7 & 3,0 \\
\hline 100 & 29,5 & 3,08 & 14,5 & 4,5 & 3,2 \\
\hline 200 & 30,5 & 3,07 & 14,1 & 4,6 & 3,1 \\
\hline 400 & 30,9 & 3,07 & 13,8 & 4,4 & 3,2 \\
\hline 800 & 28,4 & 3,02 & 14,3 & 4,9 & 2,9 \\
\hline Teste F & Ns & ns & ns & ns & ns \\
\hline $\mathrm{CV}(\%)$ & 7,8 & 3,9 & 5,3 & 7,7 & 8,5 \\
\hline Média geral & 29,8 & 3,08 & 14,2 & 4,6 & 3,1 \\
\hline
\end{tabular}

${ }^{1}$ Rend.=rendimento em suco; SST=sólidos solúveis totais; AC=acidez; SST/AC=relação entre sólidos solúveis totais e acidez titulável.

TABELA 3 - Qualidade dos frutos (\%) do maracujá-amarelo, em 17 meses de produção, em função de fontes de nitrogênio. Cruz das Almas-BA, janeiro/2000-janeiro/2002.

\begin{tabular}{|c|c|c|c|c|c|c|}
\hline Fontes de $\mathbf{N}$ & $\begin{array}{c}\text { PFS }^{1} \\
(\%)\end{array}$ & $\begin{array}{c}\text { PFV } \\
(\%)\end{array}$ & $\begin{array}{c}\text { PFA } \\
(\%)\end{array}$ & $\begin{array}{l}\text { PFS } \\
(\%)\end{array}$ & $\begin{array}{l}\text { PFV } \\
(\%)\end{array}$ & $\begin{array}{l}\text { PFA } \\
(\%)\end{array}$ \\
\hline & \multicolumn{3}{|c|}{-- setembro a dezembro/2000 -- } & \multicolumn{3}{|c|}{-- janeiro/2001 a janeiro/2002 -- } \\
\hline Uréia & 35,5 & 62,4 & 2,1 & 32,6 & 67,3 & 0,1 \\
\hline Nitrato de cálcio & 33,0 & 64,0 & 3,0 & 32,3 & 67,6 & 0,1 \\
\hline Teste F & ns & ns & ns & ns & ns & ns \\
\hline
\end{tabular}

${ }^{1} \mathrm{PFS}=$ porcentagem de frutos sadios; $\mathrm{PFV}=$ porcentagem de frutos com verrugose; PFA= porcentagem de frutos com antracnose. 


\section{CONCLUSÕES}

1) A produtividade máxima de frutos, $34,3 \mathrm{t} \mathrm{ha}{ }^{-1}$, foi obtida com aplicação de $457 \mathrm{~kg}$ de $\mathrm{N} \mathrm{ha}^{-1}$, na forma de uréia.

2) A adubação nitrogenada e as fontes utilizadas (uréia e nitrato de cálcio) não influenciaram nas características do fruto e na qualidade do suco.

\section{REFERÊNCIAS}

BAUMGARTNER, J.G. Nutrição e adubação. In: RUGGIERO, C. (Ed.). Maracujá. Ribeirão Preto: UNESP, 1987. p. 8696.

BORGES, A.L. Adubação para o maracujazeiro irrigado em solo de Tabuleiro Costeiro. Cruz das Almas: EMBRAPA-CNPMF, 1999. 2p. (Maracujá em Foco, 17).

BORGES, A.L.; CARDOSO, S. da S. Nutrição e fertirrigação do maracujazeiro. In: SIMPÓSIO BRASILEIRO SOBRE A CULTURA DO MARACUJAZEIRO, 6., 2003, Campos dos Goytacazes. Anais... Campos dos Goytacazes: UENF/UFRRJ, 2003. 1 CD-Rom

BORGES, A.L.; LIMA, A. de A.; CALDAS, R.C. Nitrogênio, fósforo e potássio na produção e qualidade dos frutos de maracujá amarelo - primeiro ano. In: SIMPÓSIO BRASILEIRO SOBRE ACULTURA DO MARACUJAZEIRO, 5., 1998, Jaboticabal. Anais... Jaboticabal: FUNEP/FCAV-UNESP/SBF, 1998. p.340-342.

BORGES, A.L.; SILVA, D.J. Fertilizantes para fertirrigação. In: BORGES, A.L.; COELHO, E.F.; TRINDADE, A.V. (Org.). Fertirrigação em fruteiras tropicais. Cruz das Almas: Embrapa Mandioca e Fruticultura, 2002. p.15-27.

CARVALHO, A.J.C. de; MARTINS, D.P.; MONNERAT, P.H.; BERNARDO, S. de. Adubação nitrogenada e irrigação no maracujazeiro-amarelo. I Produtividade e qualidade dos frutos. Pesquisa Agropecuária Brasileira, Brasília, v.35, n.6, p.1101-1108, 2000.

COELHO, A.M. Fertigação. In: COSTA, E.F. da; VIEIRA, R.F.; VIANA, P.A. (Ed.). Quimigação: aplicação de produtos químicos e biológicos via irrigação. Brasília: SPI, 1994. p.201-227.
DUTRA, G.A.P.; FONTES, P.S.F.; CARVALHO, A.J.C. de; CEREJA, B.S.; MILHOMEM, A.C.P.; MARINHO, C.S. Adubação nitrogenada nos sistemas fertirrigado e manual na cultura do maracujazeiro-amarelo 1: qualidade dos frutos. In: SIMPÓSIO BRASILEIRO SOBRE ACULTURA DO MARACUJAZEIRO, 6. 2003, Campos dos Goytacazes. Anais... Campos: UENF/UFRRJ, 2003. 1CD-Rom.

EMBRAPA. Centro Nacional de Pesquisa de Solos. Manual de métodos de análise de solo. 2.ed. Rio de Janeiro: Centro Nacional de Pesquisa de Solos, 1997. 212p.

HAAG, H.P.; OLIVEIRA, G.D.; BORDUCCHI, A.S.; SARRUGE, J.R.; Absorção de nutrientes por duas variedades de maracujá. Anais da ESALQ, Piracicaba, v.30, p.267-279, 1973.

KLIEMANN, H.J.; CAMPELO JR., J.H.; AZEVEDO, J.A. de; GUILHERME, M.R.; GEN, P.J. de C. Nutrição mineral e adubação do maracujazeiro (Passiflora edulis Sims). In: HAAG, H.P. (Ed.). Nutrição mineral e adubação de frutíferas tropicais no Brasil. Campinas: Fundação Cargill, 1986. p.245 284.

MALAVOLTA, E.; VITTI, G.C.; OLIVEIRA, S.A. de. Avaliação do estado nutricional das plantas: princípios e aplicações. Piracicaba: POTAFOS, 1989.201p.

SOUZA, L. da S. Adubação do maracujá na fazenda Cajuba, em Nova Soure, Bahia: um estudo de caso. Cruz das Almas: EMBRAPACNPMF, 1988. (relatório).

SAS INSTITUTE. SAS/STAT User's Guide. v. 8.2. Cary NC: Sas Institute, 2005. v.2.

SOUZA, L. da S.; SOUZA, L.D. Caracterização físico-hídrica de solos da área do Centro Nacional de Pesquisa de Mandioca e Fruticultura Tropical. Cruz das Almas: Embrapa Mandioca e Fruticultura, 2001.56p. (Boletim de Pesquisa e Desenvolvimento, 20).

TISDALE, S.L.; NELSON, W.L. Fertilidad de los suelos y fertilizantes. México, DF: LIMUSA, 1991.760p.

TOCCHINI, R.P.; NISIDA, A.L.A.C.; MEDINA, J.C.; TURATTI, J.M. Processamento: produtos, caracterização e utilização. In: ITAL. Maracujá: cultura, matéria-prima, processamento e aspectos econômicos. Campinas, 1995. p.161-195. 